\title{
Correction to: Transparent conductive organic-inorganic hybrid composites based on Ag nanowires
}

\author{
Katharina Lang ${ }^{1} \cdot$ Matthias Klein ${ }^{1} \cdot$ Gerhard Domann ${ }^{1} \cdot$ Peer Löbmann ${ }^{1}{ }^{1}$
}

Published online: 25 July 2020

(c) Springer Science+Business Media, LLC, part of Springer Nature 2020

\section{Correction to: Journal of Sol-Gel Science and Technology} https://doi.org/10.1007/s10971-020-05330-y

The author would like to correct the errors in the publication of the original article. The corrected details are given below.

(a). The units for specific resistance has been corrected as " $[\Omega \mathrm{cm}]$ " in line 3 of Table 1.

(b). The units for specific resistance has been corrected as " $[\Omega \mathrm{cm}]$ " in line 6 of 17th paragraph of section "Results and discussion".

Table 1 Properties of different AgNW composite films

\begin{tabular}{llll}
\hline Matrix system & Silicone & Nonpolar hybrid & Polar hybrid \\
\hline Treatment temperature $\left[{ }^{\circ} \mathrm{C}\right]$ & 220 & 230 & 250 \\
Film thickness $[\mu \mathrm{m}]$ & 330 & 290 & 225 \\
Sheet resistance $[\Omega \square]$ & 4.58 & 4.84 & 7.23 \\
Specific resistance $[\Omega \mathrm{cm}]$ & $1.51 \mathrm{E}-04$ & $1.40 \mathrm{E}-04$ & $1.63 \mathrm{E}-04$ \\
Transmittance at $550 \mathrm{~nm}[\%]$ & 79 & 76 & 63 \\
\hline
\end{tabular}

The original article can be found online at https://doi.org/10.1007/ s10971-020-05330-y.

Peer Löbmann

peer.loebmann@isc.fraunhofer.de

1 Fraunhofer-Institut für Silicatforschung, Neunerplatz 2, 97082 Würzburg, Germany
The above data show excellent results regarding processing parameters and optoelectronic properties. While TCOs require high posttreatment temperatures exceeding $300^{\circ} \mathrm{C}$ the silver nanowire composites can be cured and activated at lower temperatures. Furthermore, a comparison of the specific resistances $\left(\sim 1 \times 10^{-4} \Omega \mathrm{cm}\right)$ with the commonly used conductive oxides illustrates good electrical properties for technical performances and are in no way inferior to them [37].

The original article has been corrected. 